\title{
Chaperone gp96 mediates ER-a36 cell membrane expression
}

\author{
Junwei Hou ${ }^{1}$, Mengmeng Deng ${ }^{1}$, Xin Li ${ }^{1}$, Weiwei Liu ${ }^{1}$, Xiaoyu Chu ${ }^{1}$, Jing Wang ${ }^{2}$, \\ Feng Chen ${ }^{2}$, Songdong Meng ${ }^{1}$ \\ ${ }^{1}$ CAS Key Laboratory of Pathogenic Microbiology and Immunology, Institute of Microbiology, Chinese Academy of Sciences \\ (CAS), Beijing 100101, P.R. China \\ ${ }^{2}$ Shenogen Pharma Group, Changping District, Beijing 102206, P.R. China \\ Correspondence to: \\ Songdong Meng, e-mail: mengsd@im.ac.cn \\ Feng Chen, e-mail: feng.chen@shenogen.com \\ Keywords: ER-a36, gp96, ubiquitin, MAPK, breast cancer
}

Received: April 26, 2015

Accepted: August 28, 2015

Published: September 10, 2015

\section{ABSTRACT}

ER (estrogen receptor)-a36, a variant of human ERa, activates non-genomic cell signaling pathways. ER-a36 on the cell membrane plays a role in breast cancer growth and development, and contributes to tamoxifen resistance. However, it is not understood how cell membrane expression of ER-a36 is regulated. In this study, we investigated the role of cell membrane glycoprotein 96 (mgp96) in the regulation of ER-a36 expression and signaling. We found that the C-terminal domain of mgp96 directly interacts with ER-a36 on the cell membrane of breast tumor cells. This interaction stabilizes the ER-a36 protein, thereby increasing its signaling, which, in turn, increases tumor cell growth and invasion. Moreover, targeting mgp96 with SiRNA or monoclonal antibody (mAb) blocks the mgp96-ER-a36 interaction and inhibits breast cancer growth and invasion both in vitro and in vivo. These results provide insights into the modulation of cell membrane ER-a36 expression and suggest that mgp96 could be a potential therapeutic target for ER-a36-overexpressing breast cancer.

\section{INTRODUCTION}

Breast cancer accounts for $22.9 \%$ of all cancers in women [1]. It is a hormone-dependent disease, with estrogens playing a dominant role in both cancer initiation and progression. The biological activities of estrogens are mediated through estrogen receptors (ERs), which are expressed by nearly $70 \%$ of breast tumors. Thus, tamoxifen, an ER agonist, has been used to treat ER-positive breast cancer for over 30 years [2]. However, many patients with ER-positive tumors develop resistance to tamoxifen therapy, posing a challenge for treatment [3].

ER- $\alpha 36$, a variant of human ER $\alpha$, is involved in tamoxifen resistance. Compared to full-length $(66 \mathrm{kDa})$ $\mathrm{ER} \alpha, \mathrm{ER}-\alpha 36$ lacks both transcriptional activation domains (AF-1 and AF-2) while retaining the DNA-binding domain and partial dimerization and ligand-binding domains [4]. Its C-terminal 27-amino acid domain is unique and takes the place of the last 138 amino acids encoded by exons 7 and 8 of the ESR 1 gene. ER- $\alpha 36$ is mainly expressed in the cytoplasm, as well as on the cell surface where it mediates non-genomic estrogen and anti-estrogen signaling via intracellular signaling pathways (such as MAPK/ERK) and promotes cell growth [5].

ER- $\alpha 36$ signaling via MAPK/ERK and PI3K/AKT pathways promotes tamoxifen actions in endometrial cancer cells [6]. ER- $\alpha 36$ also increases Epidermal Growth Factor Receptor (EGFR) expression and decreases ER $\alpha$ expression, which could be an underlying mechanism for acquired tamoxifen resistance in breast cancer [7]. Moreover, approximately $40 \%$ of ER $\alpha$-positive breast cancer patients have high levels of ER- $\alpha 36$ in their tumors, and this subset of patients are less likely to receive benefits from tamoxifen therapy compared to those with $\mathrm{ER} \alpha$ positive/ER- $\alpha 36$-negative tumors [5].

GRP94, also known as gp96, is an endoplasmic reticulum-resident member of the cytosolic heat shock protein 90 (HSP90) family. Gp96 is a molecular chaperone participating in glycoprotein folding and facilitating the degradation of misfolded proteins [8]. Interestingly, the 
endoplasmic reticulum-resident gp96 translocates to the cell membrane in certain tumor cells $[9,10]$. Moreover, membrane expression of mgp96 is related to malignancy in breast cancer [11], and elevated gp96 correlates with tumor progression and ER- $\alpha 36$ expression in gastric cancer [12].

We previously found that mgp96 binds to human epidermal growth factor 2 (HER2) and EGFR, facilitating HER2 dimerization and signaling and promoting breast tumor growth [13]. ER- $\alpha 36$ also physically interacts with EGFR and HER2 and promotes malignant growth of breast cancer cells [14, 15]. Given the important roles of cell membrane ER- $\alpha 36$ in breast cancer growth and tamoxifen resistance, we investigated the role of mgp96 in the regulation of ER- $\alpha 36$ expression on the cell membrane. Our results offer a new therapeutic strategy for breast cancer treatment.

\section{RESULTS}

\section{ER-a36 binds to gp96 on the cell membrane of breast cancer cells}

To determine whether gp96 interacts with ER- $\alpha 36$ in breast cancer cells, we performed a co-IP assay with anti-gp96 polyclonal antibody in ER- $\alpha 36$-positive MDAMB-231 cells [14]. We found that gp96 interacts with ER- $\alpha 36$ in breast cancer cells (Figure 1A). Similar results were observed when the co-IP assay was performed with membrane proteins from MDA-MB-231 cells, but not with membrane proteins from ER- $\alpha 36$-negative MCF710A cells (Figure 1B), indicating the specificity of gp96 binding to ER- $\alpha 36$ on the cell surface. The interaction between gp96 and ER- $\alpha 36$ was further confirmed by GST pull-down assay (Figure 1C). To determine the region of gp96 involved in the gp96-ER- $\alpha 36$ interaction, we expressed a variety of truncated gp96 fragments (C243: aa 540-782, M163: aa 377-539, N355: aa 22-376). As shown in Figure 1D, the C-terminal domain of gp96, C243 (aa 540-782), interacted with ER- $\alpha 36$. Furthermore, confocal microscopy analysis showed that gp96 partly co-localized with ER- $\alpha 36$ on the cell membrane of ER-a36-positive MDA-MB-231 and SKBR3 cells but not on the cell membrane of ER- $\alpha 36$-negative MCF7-10A cells (Figure 1E). Next, cross-linking and co-IP with anti-gp96 polyclonal antibody was performed on the cell membrane of MDA-MB-231 cells. As shown in Figure 1F, gp96 associated with ER- $\alpha 36$ on the cell membrane.

\section{mgp96 positively regulates ER- $\alpha 36$ expression and enhances cell proliferation and invasion}

We next examined the effect of gp96 on ER- $\alpha 36$ expression. In our previous study, we found that gp 96 was highly expressed on the membrane of MDA-MB-231 and SKBR3 cells and lowly expressed on BT-474 and
T47D cells [13]. As shown in Figure 2A and 2B, gp96 knockdown significantly decreased both total and cell membrane ER- $\alpha 36$ levels. Compared to mock, depletion of gp96 decreased cell membrane ER- $\alpha 36$ in SKBR3 and MDA-MB-231 cells by $66.7 \%$ and $63.6 \%$, respectively (both $P<0.01$ ). Conversely, overexpression of mgp96 caused a dramatic increase in total (Figure 2C) and cell membrane (Figure 2D) ER- $\alpha 36$ levels. Overexpression of mgp96 increased cell membrane ER- $\alpha 36$ in BT-474 and T47D cells by $\sim 4$-fold and $\sim 5$-fold, respectively (both $P<0.01)$. However, there was no change in ER- $\alpha 36$ mRNA levels with gp96 knockdown or overexpression (data not shown), indicating that mgp96 does not regulate ER-a36 transcription.

Next we examined the impact of mgp96 on ER- $\alpha 36$ protein stability. Gp96 siRNA-treated cells showed a sharper time-dependent decrease in ER- $\alpha 36$ protein compared to mock-treated cells (Figure 2E), indicating that mgp96 affects ER- $\alpha 36$ protein stability. As ER $\alpha$ degradation mainly occurs via the ubiquitin-proteasome pathway [19-21], we quantified ER- $\alpha 36$ ubiquitination. As shown in Figure 2F, gp96 siRNA-treated cells had more ubiquitinated ER- $\alpha 36$ protein than mock-treated cells, suggesting that mgp96 regulates ER- $\alpha 36$ protein levels via the ubiquitin-proteasome degradation pathway.

ER- $\alpha 36$ promotes breast tumor growth through the MAPK signaling pathway [22]. As shown in Figure 3A, gp96 knockdown decreased ERK phosphorylation (P-ERK) and led to a decreased ratio of P-ERK to P-p38. MDA-MB-231 cells with low HER2 expression were selected to determine the effect of targeting gp96 on cell proliferation and invasion, excluding the possibility that gp96 may affect cell growth via regulating HER2 dimerization [13]. As expected, gp96 depletion inhibited cell proliferation (Figure 3B) and invasion (Figure 3C) in both MDA-MB-231 cells and SKBR3 cells (Figure 3D). To further determine the effects of gp96 RNAi on cell growth via reduced ER- $\alpha 36$, an ER- $\alpha 36$ expression vector was transfected into the MDA-MB-231-gp96i cells. The result showed that inhibition of cell proliferation by gp96 knock-down was completely reversed by ER- $\alpha 36$ overexpression (Figure 3E).

\section{An anti-gp96 mAb blocks the mgp96-ER- $\alpha 36$ interaction}

Multiple monoclonal antibodies against gp96 have been generated by our lab, and for this study we selected a gp96 mAb that efficiently blocks the activity of cell surface gp96 [18, 23]. Cross-linking and co-IP analyses revealed that the gp96 mAb blocked the association of ER- $\alpha 36$ with mgp96 (Figure 4A). Treatment of MDAMB-231 and SKBR3 cells with the gp96 mAb reduced cell membrane ER- $\alpha 36$ levels ( $\sim 60 \%$ and $\sim 75 \%$, respectively) (Figure 4B) and total ER- $\alpha 36$ protein levels (Figure 4C), and increased ER- $\alpha 36$ ubiquitination (Figure 4D). 
A

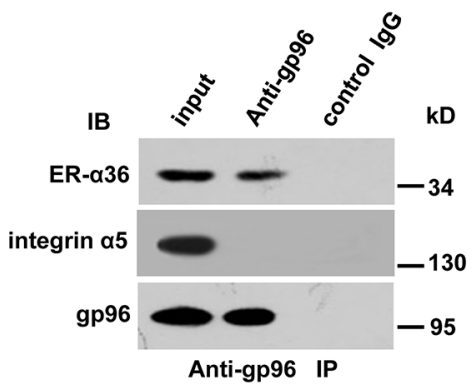

B
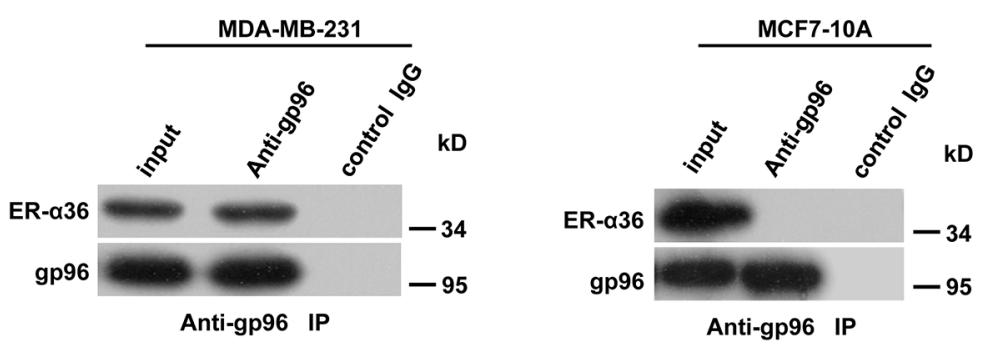

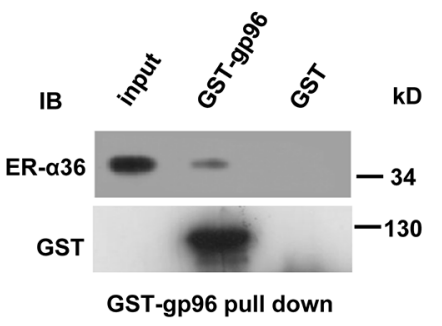

D

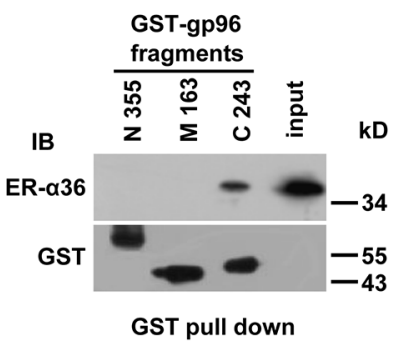

$\mathbf{E}$

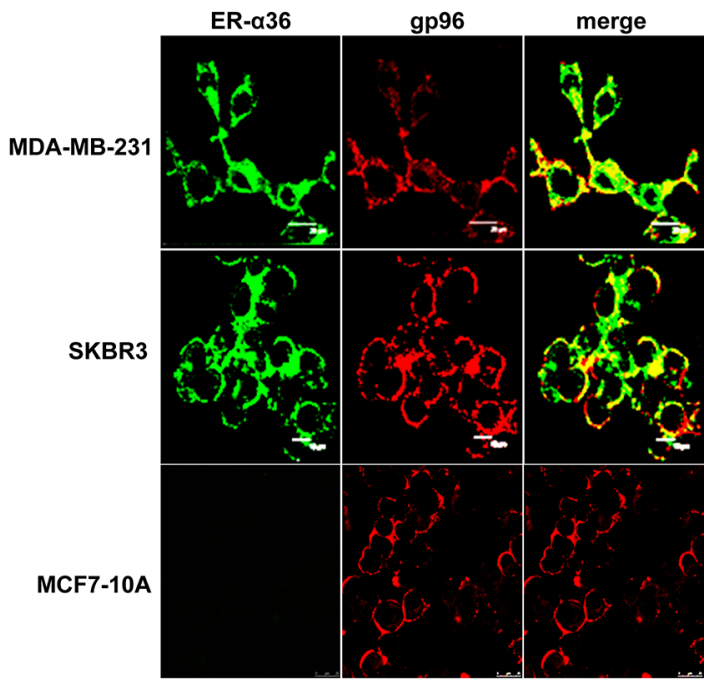

Figure 1: ER- $\alpha 36$ interacts with gp96 on the cell membrane of breast cancer cells. A. and B. Co-IP assay with the anti-gp96 polyclonal antibody using total cell lysates (A) or cell membrane proteins (B) to test for the interaction between gp96 and ER- $\alpha 36$ in MDA-MB-231 and MCF7-10A cells. Cell membrane integrin $\alpha 5$ served as a negative control. C. and D. In vitro GST pull-down assays with purified GST-gp96 (C) or GST-gp96 fragments (N355, M163 and C243) (D) E. Detection of gp96 and ER- $\alpha 36$ by confocal microscopy in unpermeabilized SKBR3, MDA-MB-231, and MCF7-10A cells. Scale bar, $20 \mu \mathrm{m}$. F. Co-IP with the anti-gp96 polyclonal antibody in SKBR3 cells cross-linked with DTSSP. Cells were washed with cold PBS three times and cross-linked with membrane-nonpermeable, thiol-cleavable DTSSP (final concentration; $2 \mathrm{mM}$ ) on ice for $30 \mathrm{~min}$. Cell lysates were immunoprecipitated with the anti-gp96 polyclonal antibody, and the immunoprecipitates were treated with or without DTT, and subjected to Western blot.

Treatment of MDA-MB-231 cells with the gp96 mAb also significantly inhibited ER- $\alpha 36$-mediated MAPK signaling (Figure 4E) and pronouncedly suppressed cell growth (Figure 4F) and invasion (Figure 4G). The inhibitory effect of the gp96 mAb on cell growth was also observed in SKBR3 cells (Figure 4H).

\section{Targeting gp96 inhibits breast cancer tumor growth}

To determine whether gp96 targeting could be an effective strategy to inhibit breast tumor growth in vivo, we generated a stable gp96-knockdown cell line, MDAMB-231-gp96i. Similar to our in vitro results, tumor growth was significantly slowed in MDA-MB-231gp96i xenograft nude mice compared to mock $(P<0.05)$
(Figure 5A). Gp96 depletion resulted in a 39.7\% decrease in tumor weights $(P<0.01)$ (Figure 5B). Gp96 knockdown in tumors also decreased ER- $\alpha 36$ expression compared to mock (Figure 5C).

We next determined the therapeutic effect of the gp96 mAb in MDA-MB-231 xenograft nude mice. As shown in Figure 5D and 5E, treatment with the gp96 mAb dramatically slowed tumor growth $(P<0.05)$ and decreased tumor burden by $51.7 \%(P<0.05)$ compared to mice treated with control antibody. Treatment with gp96 mAb also decreased ER- $\alpha 36$ levels in xenograft tumors (Figure 5F).

Of note, the inhibitory effect of the gp96 mAb on tumor growth was mostly eliminated with simultaneously silencing ER- $\alpha 36(P>0.05)$, indicating that the gp96 mAb suppressed tumor growth through regulation of ER- $\alpha 36$ (Figure 5G, 5H). 

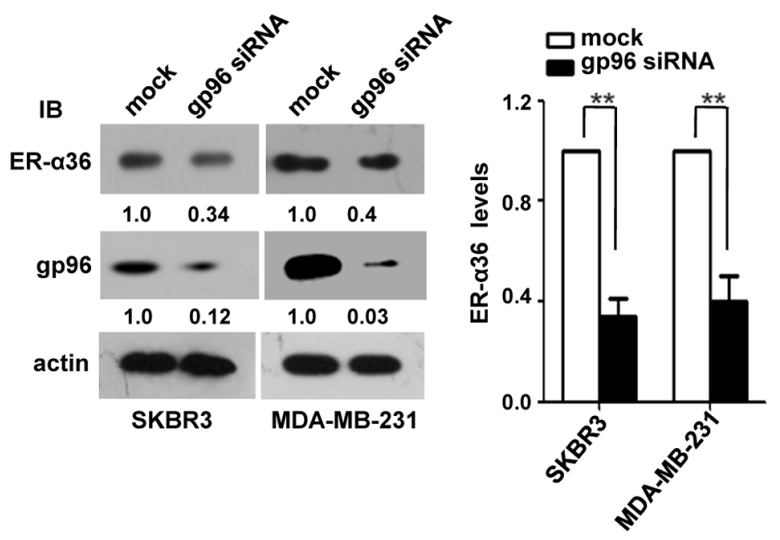

C
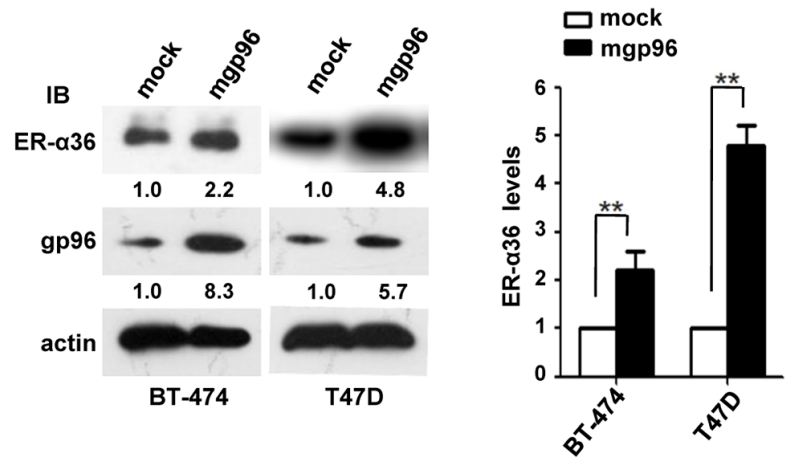

E
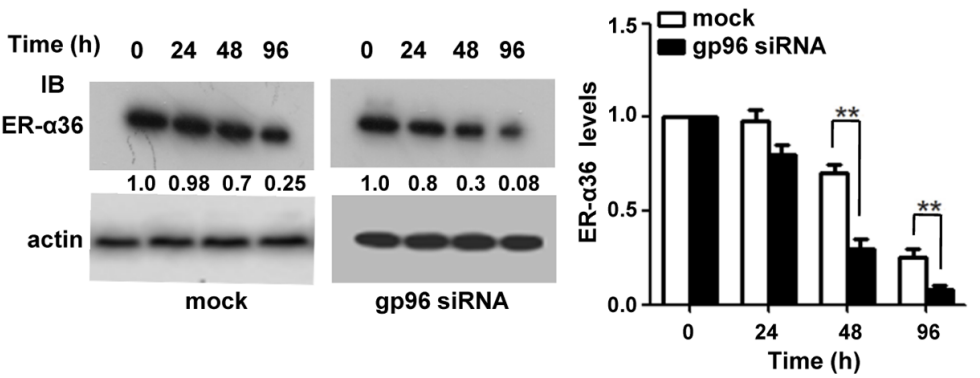

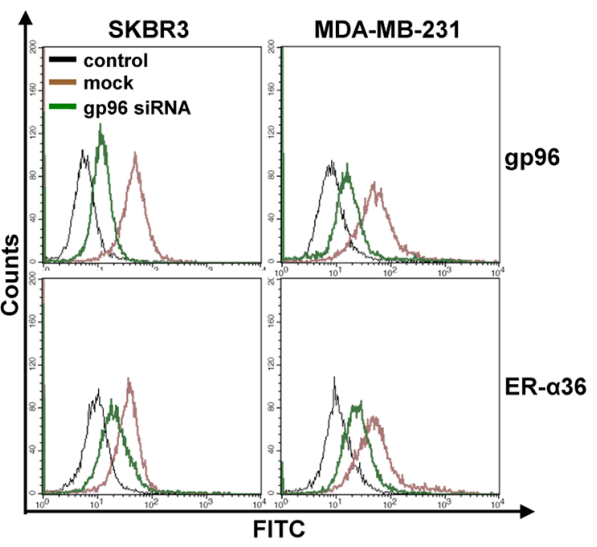

D

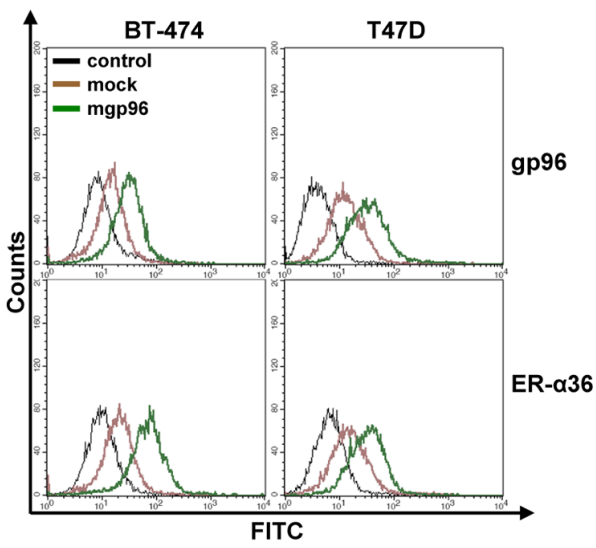

$\mathbf{F}$

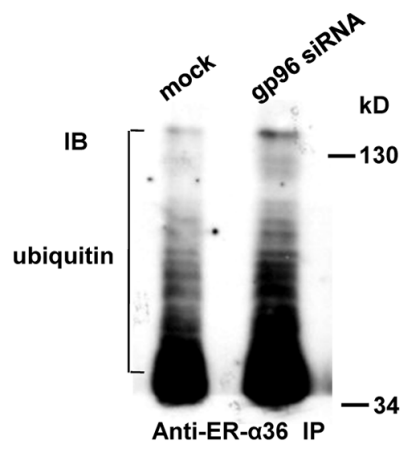

Figure 2: mgp96 upregulates the expression and stability of ER- $\alpha 36$ protein. Breast cancer cells were pretreated with DMEM without phenol red (Hyclone, USA) and containing 2.5\% fetal bovine serum (FBS) (Gibco, USA) for $48 \mathrm{~h}$ and maintained in the culture throughout the test. A. and B. SKBR3 and MDA-MB-231 cells were transfected with gp96 siRNA or control siRNA (mock) for 72 h. Total gp96 and ER- $\alpha 36$ levels were determined by Western blot and normalized by actin (A) Cell membrane gp96 and ER- $\alpha 36$ levels were detected by flow cytometry (B) Cells stained with control IgG served as a control. C. and D. BT-474 and T47D cells were infected with the adenoviruses ad-mgp96 or ad-pDC312 (mock) for $72 \mathrm{~h}$. Total and cell membrane gp96 and ER- $\alpha 36$ levels were determined by Western blot (normalized by actin) (C) and flow cytometry (D), respectively. Cells stained with control IgG served as a control. E. The stability of ER- 236 protein was analyzed using a CHX chase experiment. MDA-MB-231 cells were transfected with gp96 siRNA or control siRNA (mock) for $36 \mathrm{~h}$. Cells were then treated with $50 \mu \mathrm{g} / \mathrm{ml} \mathrm{CHX}$ for the time as indicated, and cell lysates were subjected to Western blot. ER- $\alpha 36$ levels were normalized by actin. The ratio of ER- $\alpha 36$ to actin levels at $0 \mathrm{~h}$ was set as 1.0. F. Co-IP analysis of the ubiquitinated ER- 236 protein levels in MDA-MB-231 cells. Cells were transfected with gp96 siRNA or control siRNA (mock). Seventy-two hours after the transfection, cells were treated with $10 \mu \mathrm{M}$ MG132 for $4 \mathrm{~h}$. Cell lysates were immunoprecipitated with the anti-ER- $\alpha 36$ antibody, and immunoprecipitates were subjected to Western blot. 
A

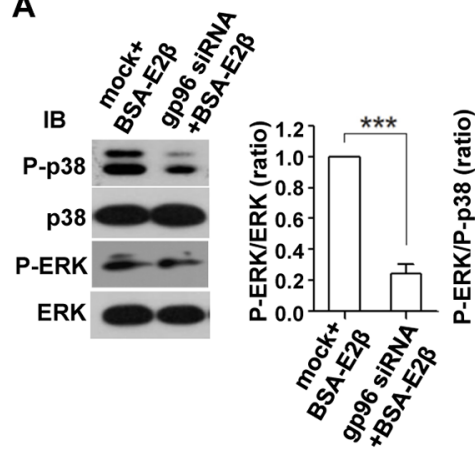

B

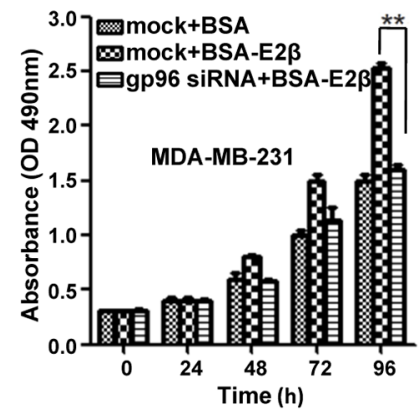

C
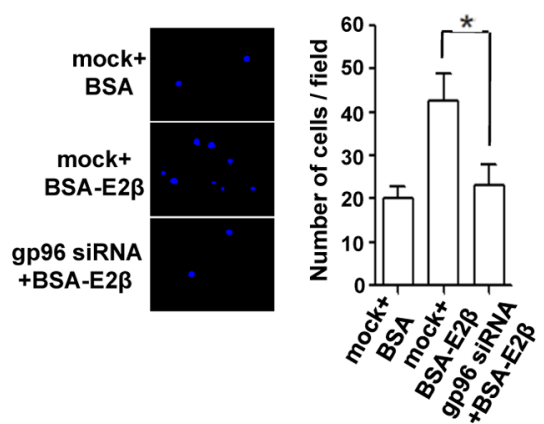

D

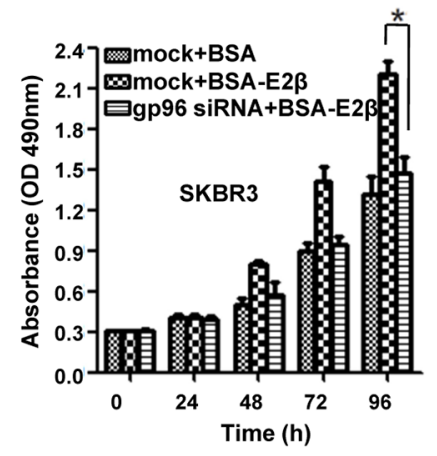

E

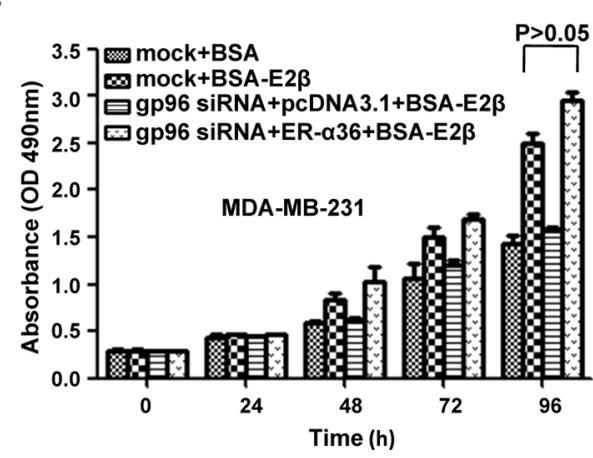

Figure 3: gp96 depletion reduces MAPK signaling and inhibits the growth and invasion of breast cancer cells. Breast cancer cells were pretreated with DMEM without phenol red and containing $2.5 \% \mathrm{FBS}$ for $48 \mathrm{~h}$ and maintained in the culture throughout the test. The stable shRNA cell lines MDA-MB-231-gp96i and MDA-MB-231-luci (mock) were treated with 50nM BSA-E2 $\beta$ for 20 min (A) $96 \mathrm{~h}$ (B) or $72 \mathrm{~h}$ (C). A. Western blot analysis of the protein levels of ERK, P-ERK, p38, and P-p38. Cell proliferation and invasion were analyzed by CCK-8 B. and transwell C. assays, respectively. D. SKBR3 cells transfected with gp 96 siRNA or control siRNA (mock) were treated with 50nM BSA-E2 $\beta$ for $96 \mathrm{~h}$, and cell proliferation was determined by CCK8 assay. E. MDA-MB-231-gp96i or MDA-MB231-luci (mock) cells transfected with pcDNA-ER- $\alpha 36$ or empty vector pcDNA3.1 as control were treated with 50nM BSA-E2 $\beta$ for $96 \mathrm{~h}$, and cell proliferation was determined by CCK8 assay. ${ }^{*} P<0.05, * * P<0.01,{ }^{* * *} P<0.001$.

\section{DISCUSSION}

ER- $\alpha 36$ overexpression has been observed in breast cancer [22, 24], adenoid cystic carcinoma (ACC), pure apocrine carcinomas (PAC) of breast [25], endometrial cancer [26], gastric cancer [27], and colorectal cancer [28]. ER- $\alpha 36$ expression is found in breast cancer tumors that are either positive or negative for ER, PR, and Her-2, indicating that ER- $\alpha 36$ might be an additional driver in the development and progression of breast cancer [29]. Due to its emerging roles in the regulation of tumorigenesis and cancer progression, ER- $\alpha 36$ therefore serves as a new potential target for therapeutic development against breast cancer. In this study, we found that mgp96 binds to and stabilizes ER- $\alpha 36$ on the cell membrane of breast cancer cells. Moreover, a gp96 $\mathrm{mAb}$ that prevents mgp96 binding to ER- $\alpha 36$ decreases ER- $\alpha 36$ signaling and suppresses breast cancer growth and invasion, both in vitro and in vivo. These results contribute to our understanding of the modulation of ER-a36 activation and validate mgp96 as a potential therapeutic target for ER- $\alpha 36$-positive breast cancer.
Since ER- $\alpha 36$ activates membrane-initiated non-genomic signaling pathways (MAPK [22, 30], AKT [6], and PKC [31]), cell membrane ER- $\alpha 36$ is thought to play a dominant role in driving breast cancer growth and development. Our results show that mgp96 binds to cell membrane ER- $\alpha 36$, increasing its stability, perhaps by decreasing ubiquitination, and leading to its up-regulation on the membrane of breast cancer cells.

The specificity of the gp96 mAb was verified in our previous study showing that the gp $96 \mathrm{mAb}$ only inhibits growth of mgp96-positive breast cancer cells, and has no effect on mgp96-negative cells [13]. Besides, there was no difference in the weight between gp96 mAb-treated mice and control IgG-treated mice, indicating that gp96 mAb inflicts no potential toxicity on mice. In addition, treatment with the gp96 mAb only inhibited proliferation of MDAMB-231 cells but not gp96-knockdown MDA-MB-231gp96i cells (data not shown). More studies are needed to determine off-target effects of the gp $96 \mathrm{mAb}$ in order to minimize its potential toxicity and improve efficacy.

A previous study revealed that palmitoylation of $E R \alpha-66$ is necessary for the localization of that particular 
A

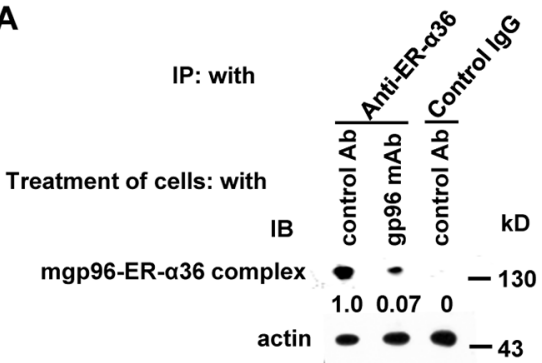

B

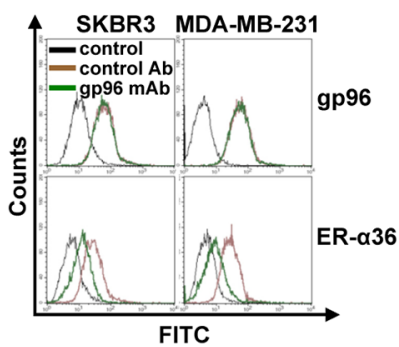

C

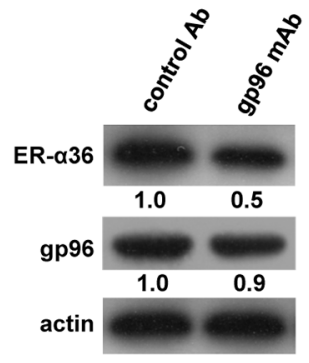

D

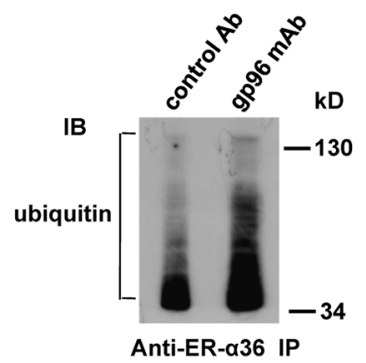

$\mathbf{E}$
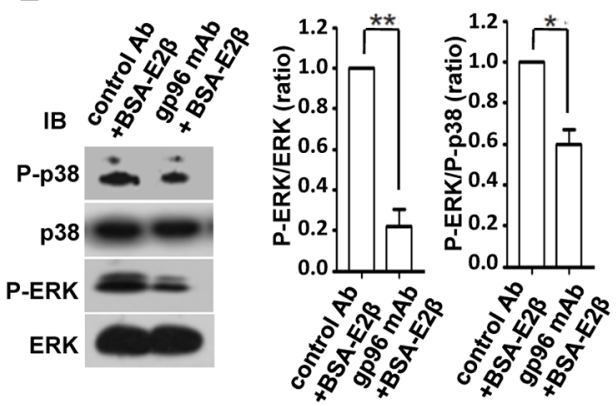

H
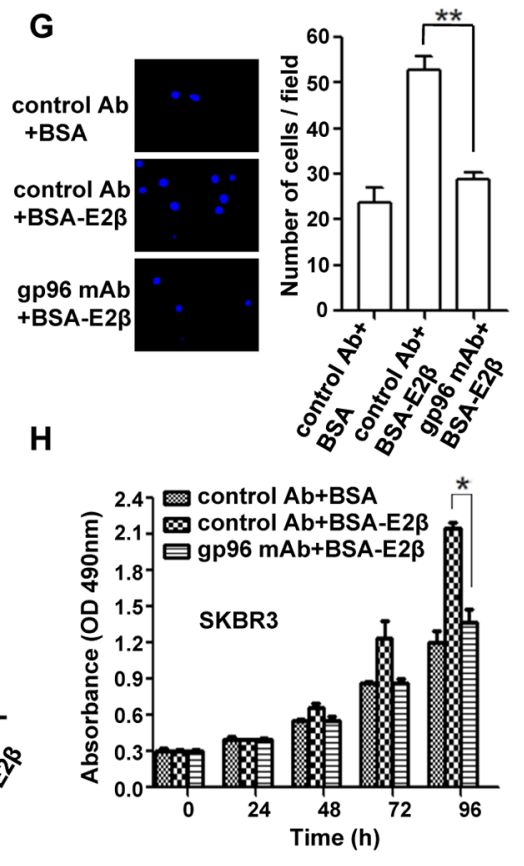

$\mathbf{F}$

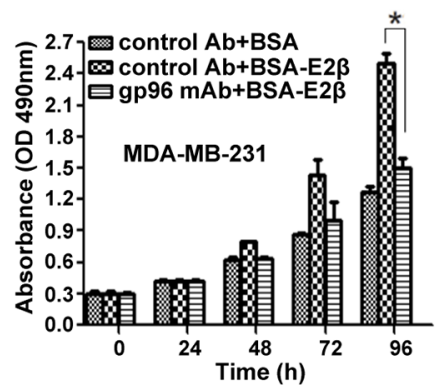

Figure 4: A gp96 mAb blocks the mgp96-ER- 36 interaction, decreases cell membrane ER- 236 levels, and suppresses growth and invasion of breast cancer cells. SKBR3 and MDA-MB-231 cells were pretreated with DMEM without phenol red and containing $2.5 \% \mathrm{FBS}$ for $48 \mathrm{~h}$ and maintained in the culture throughout the test. Cells were treated with the gp96 mAb or control antibody $(50 \mu \mathrm{g} / \mathrm{ml})$ for $8 \mathrm{~h}(\mathrm{~A}), 48 \mathrm{~h}(\mathrm{~B}-\mathrm{E})$, or $96 \mathrm{~h}(\mathrm{~F}$ and $\mathrm{H}), 72 \mathrm{~h}(\mathrm{G})$. A. Eight hours after the gp96 mAb treatment, MDA-MB-231 cells were cross-linked with the membrane-nonpermeable, thiol-noncleavable BS3 (final concentration; $2 \mathrm{mM}$ ) for 30 min on ice. Cell lysates were immunoprecipitated with the anti-ER- $\alpha 36$ monoclonal antibody, and the immunoprecipitates were subjected to Western blot. B. Cell membrane gp96 and ER- $\alpha 36$ abundance was analyzed by flow cytometry. Cells stained with control IgG served as a control. C. Western blotting analysis of total gp96 and ER- $\alpha 36$ protein levels in MDA-MB-231 cells. D. Co-IP analysis of the ubiquitinated ER- $\alpha 36$ levels in MDA-MB-231 cells. Cells treated with gp96 mAb were incubated with $10 \mu \mathrm{M} \mathrm{MG132}$ for $4 \mathrm{~h}$. Cell lysates were immunoprecipitated with the anti-ER- $\alpha 36$ antibody, and immunoprecipitates were subjected to Western blot. E. The protein levels of ERK, P-ERK, p38, and P-p38 were analyzed by Western blot in MDA-MB-231 cells co-treated with 50nM BSA-E2 $\beta$ for 20 min. F. Cell proliferation was analyzed by CCK-8 assay in MDA-MB-231 cells co-treated with 50nM BSA-E2 $\beta$ for $96 \mathrm{~h}$. G. Cell invasion was determined by transwell assay in MDA-MB-231 cells co-treated with 50nM BSA-E2 $\beta$ for 72 h. H. Cell proliferation was analyzed by CCK-8 assay in SKBR3 cells co-treated with 50nM BSA-E2 $\beta$ for 96 h. $* P<0.05, * * P<0.01$.

ER isoform to the cell membrane [32]. It remains to be determined whether post-translational modifications such as palmitoylation also play a role in ER- $\alpha 36$ targeting to the plasma membrane.

In addition to post-transcriptional regulation, ER- $\alpha 36$ transcription is also regulated by many factors. ER- $\alpha 36$ interacts with HER2 in the cytoplasm and membrane of breast cancer cells $[15,29]$. ER- $\alpha 36$ positively regulates HER2 expression, and HER2 signaling activates ER- $\alpha 36$ transcription through an AP1 site in the ESR 1 promoter. This positive feedback drives breast cancer development [15]. Additionally, the positive feedback loop of ER- $\alpha 36 /$ EGFR promotes malignant growth of ER-negative breast cancer cells [14]. As molecular chaperones, HSP90 and synuclein $\gamma$ (SNCG) also facilitate the expression of ER- $\alpha 36$ and stimulate ligand-dependent cell growth [33]. Interestingly, a recent study demonstrated that the gp96 expression levels are up-regulated by ER- $\alpha 36$ in gastric carcinoma cells [12]. Thus, it is possible that there also exists a positive feedback loop in the mgp96-ER- $\alpha 36$ interaction. 
A

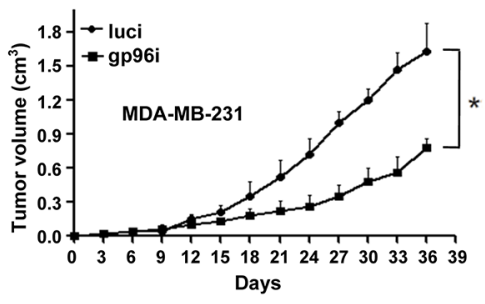

D

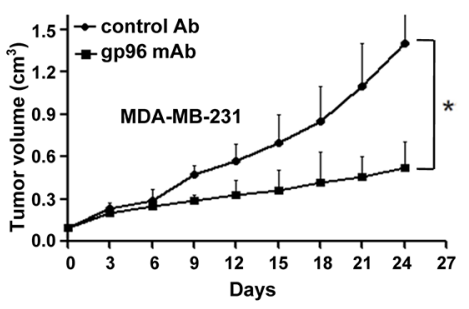

G

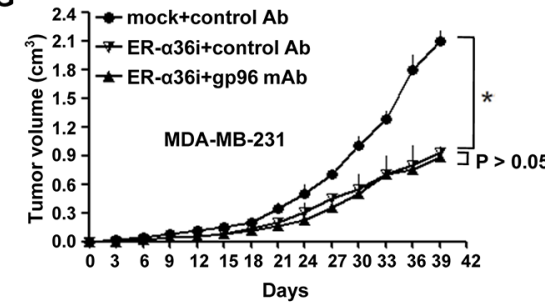

B

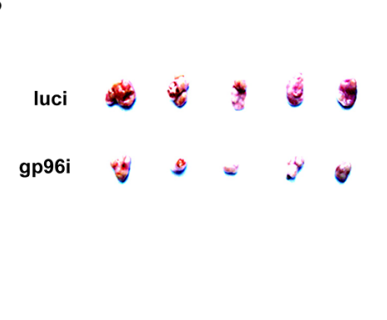

E

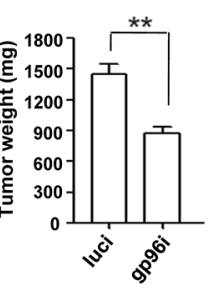

C
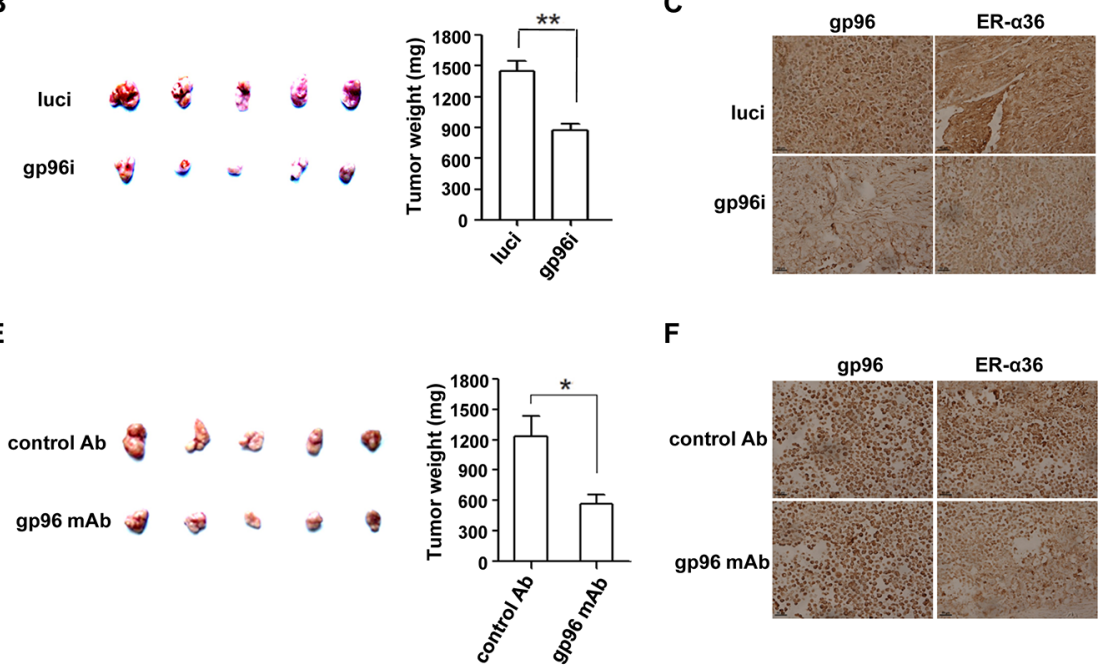

F

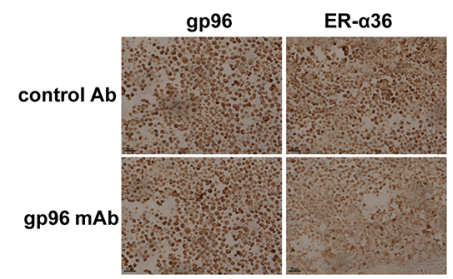

H

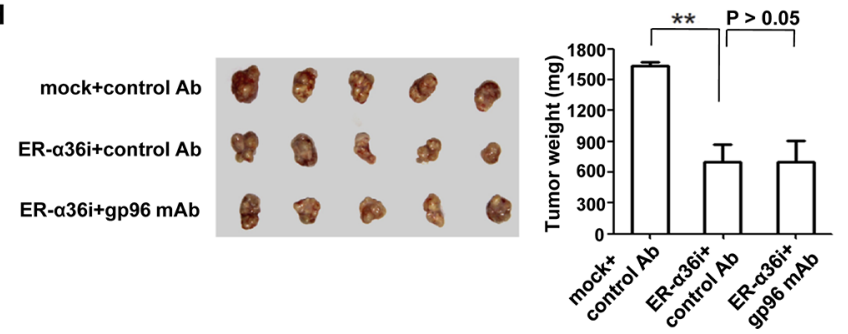

Figure 5: Targeting gp96 with shRNA or mAb leads to suppressed breast tumor growth in mice. A-C. BALB/c nude mice were injected s.c. with MDA-MB-231-gp96i or MDA-MB-231-luci (mock) cells (model 1). Tumor volume was monitored every 3 days (A) Representative image of tumor growth (left) and mean tumor weights (right) 36 days after cell injection (B) IHC analysis of gp96 and ER- $\alpha 36$ expression in tumors (C) Scale bar, $50 \mu \mathrm{m}$. D-F. BALB/c nude mice were injected s.c. with MDA-MB-231 cells and treated with the gp96 mAb or control antibody $\left(2 \mathrm{mg} / \mathrm{kg}\right.$ ) when tumors reached a volume of $\sim 100 \mathrm{~mm}^{3}$ (around 2 weeks after injection of tumor cells) (model 2). Tumor volume was monitored every 3 days (D) Representative image of tumor growth (left) and mean tumor weights (right) 3 weeks after gp96 mAb treatment (E) IHC analysis of gp96 and ER- $\alpha 36$ expression in tumors (F) Scale bar, $50 \mu \mathrm{m}$. G. and H. BALB/c nude mice were injected s.c. with MDA-MB-231-ER-a36i or MDA-MB-231-mock cells, and treated with gp96 mAb or control antibody (2mg/kg) (model 3). Tumor volume was monitored every 3 days (E) Representative image of tumor growth (left) and mean tumor weights (right) 39 days after cell injection $(\mathrm{F}) * P<0.05, * * P<0.01$.

In addition, we previously showed that mgp96 binds to HER2 and enhances HER2 signaling by facilitating HER2 dimerization in HER2-overexpressed breast cancer [13]. Targeting mgp96 with siRNA or specific mAb inhibits HER2-positive breast cancer growth. This may be due to the lack of the ER- $\alpha 36$ ligand E2 $\beta$ in the experimental system. In addition, according to a previous study, there is a positive cross-regulation between HER2 and ER- $\alpha 36$ [15]. Therefore, it is very likely that targeting mgp96 suppresses the growth of HER2-positive breast cancer through inhibition of both HER2 and ER- $\alpha 36$. We speculate that cross-talk among mgp96, ER- $\alpha 36$ and HER2 forms a positive feedback loop in breast cancer, which may affect tumor growth, metastasis, and drug resistance, but this relationship remains to be examined.

We (and others) have shown that gp96 is able to bind antigenic peptides and cross-present the associated peptides to MHC Class I molecules, activating cytotoxic $\mathrm{T}$ cell responses [34, 35]. Meanwhile, cell membrane expression of normally ER-resided gp96 is observed in multiple tumors and involved in promoting malignant growth. Targeting mgp96 with specific antibodies may therefore provide a novel therapeutic approach against cancer. More studies are needed to dissect the precise function of gp96 in the context of anti-tumor immunity and targeted therapy. ER- $\alpha 36$ mediates non-genomic estrogen and anti-estrogen (tamoxifen) signaling and stimulates cell proliferation, which contributes to tamoxifen resistance $[3,5,7]$. Given the dominant role of cell membrane ER- $\alpha 36$ in breast cancer growth and development, our study represents an effort to address the underlying mechanism of elevated cell membrane ER- $\alpha 36$ levels mediated by mgp96 in breast cancer. Moreover, our results provide a potential therapeutic strategy for ER- $\alpha 36(+)$ breast cancer via inhibition of mgp96 activity. 


\section{MATERIALS AND METHODS}

\section{Cells, viruses, antibodies, and reagents}

ER-negative breast cancer cell lines MDA-MB-231, SKBR3, BT-474, and T47D were obtained from the American Type Culture Collection (Manassas, VA, USA). Recombinant adenoviruses, ad-mgp96 expressing mgp96, and control adenoviruses ad-pDC312 were created by our lab. The ER-a36-knockdown cell line, MDA-MB231-ER-a36i, and MDA-MB-231-mock cell line, the ER-a36-negative breast cancer cell line MCF7-10A, ER- $\alpha 36$ antibody, E2 $\beta$ and BSA-E2 $\beta$ were generous gifts from Beijing Shenogen Biomedical Co. Ltd. Gp96 polyclonal antibody and Protein $G$ were purchased from Santa Cruz Biotechnology (Dallas, Texas, USA). The gp96 monoclonal antibody $(\mathrm{mAb})$ was generated in our lab. ERK antibody, Phospho-ERK antibody, p38 antibody, and Phospho-p38 antibody were purchased from Cell Signaling Technology (Danvers, Massachusetts, USA). The remaining antibodies were obtained from Zhongshan Goldenbridge Biotechnology (Beijing, China). Cycloheximide (CHX) and MG132 were from Beyotime Institute of Biotechnology (Shanghai, China). Glutathione Sepharose 4B was from GE Healthcare Life Sciences (Little Chalfont, Buckinghamshire, United Kingdom). The protein cross-linkers DTSSP and BS3 were purchased from Thermo Scientific (Waltham, Massachusetts, USA).

\section{Western blot}

Western blot analysis was performed according to our previous description [16].

\section{Co-immunoprecipitation (co-IP)}

Co-IP was performed as previously [13]. Briefly, $2 \mu \mathrm{g}$ of the relevant antibody was added to cell lysates overnight at $4^{\circ} \mathrm{C}$. Then cell lysates were immunoprecipitated with Protein G Sepharose beads for $4 \mathrm{~h}$ at $4^{\circ} \mathrm{C}$. Immunoprecipitates were separated by SDSPAGE for Western blot analysis.

\section{Subcellular fractionation}

Cell membrane proteins were isolated using a ProteoExtract $^{\mathrm{TM}}$ Subcellular Proteome Extraction Kit (Calbiochem, Germany) following the manufacturer's instructions.

\section{GST pull-down}

Briefly, $20 \mu \mathrm{g}$ of GST or GST fusion proteins was incubated with $50 \mu$ l Glutathione Sepharose 4B for $1 \mathrm{~h}$ at $4^{\circ} \mathrm{C}$, and then, cell lysates were added and incubated for $4 \mathrm{~h}$ at $4^{\circ} \mathrm{C}$. The agarose beads were washed with PBS twice and resuspended in loading buffer. After incubation in boiling water for $10 \mathrm{~min}$, the supernatant was subjected to Western blot analysis.

\section{Confocal laser scanning microscopy (CLSM)}

Confocal microscopy was performed on nonpermeabilized cells as previously described [17]. Images were obtained on a Leica TCS SP2 confocal laser-scanning microscope (Leica Microsystems, Germany).

\section{Flow cytometry}

Cells were pretreated with $0.5 \mathrm{mM}$ EDTA to facilitate removal of substrate and washed with PBS. After blocked in PBS containing 10\% BSA, cells were resuspended in a $100 \mu \mathrm{l}$ PBS volume containing $10 \%$ BSA and serially stained with primary and secondary antibodies on ice for $1 \mathrm{~h}$. Detection of fluorescence intensity was performed on a FAC-Scan cytometry machine (BD Biosciences, USA).

\section{Cell proliferation}

Cell growth was measured using a Cell Counting Kit-8 (CCK-8) (Dojindo, Japan) following the manufacturer's instructions.

\section{Cell invasion}

Cell invasion assays were performed as previously described [16].

\section{Establishment of a stable shRNA cell line}

The short hairpin RNA (shRNA) sequence targeting the gp96 gene was designed and synthesized as previously described [18]. The shRNA construct was established by inserting the oligonucleotides into the RNA interference (RNAi)-pSIREN-RetroQ vector. The recombinant plasmid, pSIREN-gp96i, was confirmed by sequencing. Luciferase shRNA was selected as a mock transfection control (pSIREN-luci). Phoenix cells were co-transfected with pSIREN-gp96i or pSIREN-luci and the helper vector. Seventy-two hours after transfection, the supernatant was collected and MDA-MB-231 cells were infected with the virus suspension. At $48 \mathrm{~h}$ after infection, MDA-MB-231 cells were selected with $2 \mu \mathrm{g} / \mathrm{ml}$ puromycin for 2 weeks to establish stable shRNA cell lines: MDA-MB-231-gp96i and MDA-MB-231-luci (mock). The protein levels of gp96 were analyzed by western blotting to confirm that gp96 was effectively silenced.

\section{Animal experiments}

Model 1 - Six-week-old female BALB/c nude mice were randomly divided into two groups $(n=5 /$ group). MDA-MB-231-gp96i or MDA-MB-231-luci 
(mock) cells were maintained in phenol red-free media with $2.5 \%$ charcoal-stripped fetal calf serum for three days, and a total of $1 \times 10^{7}$ cells were injected subcutaneously (s.c.) in the right hind flank of nude mice 5 days after s.c. implantation of $1.7 \mathrm{mg} / 60$-day release E2 pellets (Innovative Research of American, Sarasota, FL). Tumor growth was monitored every 3 days and tumor size was calculated with the formula: $\mathrm{Tv}=\left(\mathrm{L} \times \mathrm{W}^{2}\right) / 2$. Mice were sacrificed 36 days after cell injection for tumor weight evaluation and immunohistochemistry (IHC).

Model 2 - MDA-MB-231 cells were maintained in phenol red-free media with $2.5 \%$ charcoal-stripped fetal calf serum for three days, and a total of $1 \times 10^{7}$ cells were injected s.c. in the right hind flank of six-week-old female BALB/c nude mice 5 days after s.c. implantation of $1.7 \mathrm{mg} / 60$-day release E2 pellets. Tumor growth was monitored every 3 days. Mice were randomly divided to two groups ( $n=5 /$ group) when tumors reached a volume of $\sim 100 \mathrm{~mm}^{3}$ (around 2 weeks after injection of MDAMB-231 cells). Mice were treated with the gp96 mAb or control antibody (2 $\mathrm{mg} / \mathrm{kg})$ via intraperitoneal (i.p.) injection twice a week. Three weeks later, mice were sacrificed for tumor weight evaluation and IHC.

Model 3 - Six-week-old female BALB/c nude mice were implanted s.c. with $1.7 \mathrm{mg} / 60$-day release E2 pellets 5 days before cell injection and randomly divided into three groups ( $n=5 /$ group), and MDAMB-231-mock and MDA-MB-231-ER- $\alpha 36 \mathrm{i}$ cells were maintained in phenol red-free media with $2.5 \%$ charcoal-stripped fetal calf serum for three days: group 1 (231-mock+control $\mathrm{Ab})$ was injected s.c. in the right hind flank with $1 \times 10^{7}$ MDA-MB-231-mock cells, and treated with control antibody $(2 \mathrm{mg} / \mathrm{kg})$ via i.p. injection twice a week from the day 15 after cell injection; group 2 (231-ER- $\alpha 36 \mathrm{i}+$ control $\mathrm{Ab}$ ) was injected s.c. in the right hind flank with $1 \times 10^{7}$ MDA-MB-231-ERa36i cells, and treated with control antibody $(2 \mathrm{mg} / \mathrm{kg})$ via i.p. injection twice a week from the day 15 after cell injection; group 3 (231-ER- $\alpha 36 \mathrm{i}+\mathrm{gp} 96 \mathrm{mAb}$ ) was injected s.c. in the right hind flank with $1 \times 10^{7} \mathrm{MDA}-$ MB-231-ER- $\alpha 36 \mathrm{i}$ cells, and treated with gp96 mAb $(2 \mathrm{mg} / \mathrm{kg}$ ) via i.p. injection twice a week from the day 15 after cell injection. Tumor growth was monitored every 3 days. All mice were sacrificed at the day 39 after cell injection for tumor weight evaluation.

Mice were maintained and cared for in strict compliance with the institution's guidelines of the Institute of Microbiology, Chinese Academy of Sciences of Research Ethics Committee. All procedures were approved by the Research Ethics Committee.

\section{Immunohistochemistry (IHC)}

IHC analysis of paraffin-embedded mouse tumors was performed as described previously [18].

\section{Statistical analysis}

All data are presented as the mean $\pm \mathrm{SD}$, and significance was determined by two-tailed Student's t test. A $P$ value of less than 0.05 was considered statistically significant.

\section{ACKNOWLEDGMENTS}

This work was supported by a grant from Major State Basic Research Development Program of China (973 Program) (No.2014CB542602), grants from the National Natural Science Foundation of China (31230026, $81321063,81102018,81471960)$, and a grant from the Beijing Nova Program (No. Z141102001814084).

\section{GRANT SUPPORT}

This work was supported by a grant from Major State Basic Research Development Program of China (973 Program) (No. 2014CB542602), grants from the National Natural Science Foundation of China (31230026, 81321063, 81102018, 81471960), and a grant from the Beijing Nova Program (No. Z141102001814084).

\section{CONFLICTS OF INTEREST}

No potential conflicts of interest were disclosed.

\section{REFERENCES}

1. Karimi P, Shahrokni A, Moradi S. Evidence for U.S. Preventive Services Task Force (USPSTF) recommendations against routine mammography for females between 40-49 years of age. Asian Pac J Cancer Prev. 2013; 14:2137-2139.

2. Chang M. Tamoxifen Resistance in Breast Cancer. Biomol Ther (Seoul). 2012; 20:256-267.

3. Fowler AM, Santen RJ, Allred DC. "Dwarf" estrogen receptor in breast cancer and resistance to tamoxifen. J Clin Oncol. 2009; 27:3413-3415.

4. Wang Z, Zhang X, Shen P, Loggie BW, Chang Y, Deuel TF. Identification, cloning, and expression of human estrogen receptor-alpha36, a novel variant of human estrogen receptor-alpha 66. Biochem Biophys Res Commun. 2005; 336:1023-1027.

5. Shi L, Dong B, Li Z, Lu Y, Ouyang T, Li J, Wang T, Fan Z, Fan T, Lin B, Wang Z, Xie Y. Expression of ER-\{alpha\} 36 , a novel variant of estrogen receptor $\{$ alpha\}, and resistance to tamoxifen treatment in breast cancer. J Clin Oncol. 2009; 27:3423-3429.

6. Lin SL, Yan LY, Zhang XT, Yuan J, Li M, Qiao J, Wang ZY, Sun QY. ER-alpha36, a variant of ER-alpha, 
promotes tamoxifen agonist action in endometrial cancer cells via the MAPK/ERK and PI3K/Akt pathways. PLoS One. 2010; 5:e9013.

7. Li G, Zhang J, Jin K, He K, Zheng Y, Xu X, Wang H, Wang H, Li Z, Yu X, Teng X, Cao J, et al. Estrogen receptor- $\alpha 36$ is involved in development of acquired tamoxifen resistance via regulating the growth status switch in breast cancer cells. Mol Oncol. 2013; 7:611-624.

8. Christianson JC, Shaler TA, Tyler RE, Kopito RR. OS-9 and GRP94 deliver mutant alpha1-antitrypsin to the Hrd1SEL1L ubiquitin ligase complex for ERAD. Nat Cell Biol. 2008; 10:272-282.

9. Altmeyer A, Maki RG, Feldweg AM, Heike M, Protopopov VP, Masur SK, Srivastava PK. Tumor-specific cell surface expression of the-KDEL containing, endoplasmic reticular heat shock protein gp96. Int J Cancer. 1996; 69:340-349.

10. Robert J, Ménoret A, Cohen N. Cell surface expression of the endoplasmic reticular heat shock protein gp96 is phylogenetically conserved. J Immunol. 1999; 163:4133-4139.

11. Melendez K, Wallen ES, Edwards BS, Mobarak CD, Bear DG, Moseley PL. Heat shock protein 70 and glycoprotein 96 are differentially expressed on the surface of malignant and nonmalignant breast cells. Cell Stress Chaperones. 2006; 11:334-342.

12. Fu Z, Deng $H$, Wang $X$, Yang $X$, Wang $Z$, Liu L. Involvement of ER- $\alpha 36$ in the malignant growth of gastric carcinoma cells is associated with GRP94 overexpression. Histopathology. 2013; 63:325-333.

13. Li X, Sun L, Hou J, Gui M, Ying J, Zhao H, Lv N, Meng S. Cell membrane gp96 facilitates HER2 dimerization and serves as a novel target in breast cancer. Int J Cancer. 2015; 137:512-524.

14. Zhang XT, Kang LG, Ding L, Vranic S, Gatalica Z, Wang ZY. A positive feedback loop of ER- $\alpha 36 /$ EGFR promotes malignant growth of ER-negative breast cancer cells. Oncogene. 2011; 30:770-780.

15. Kang L, Guo Y, Zhang X, Meng J, Wang ZY. A positive cross-regulation of HER2 and ER- $\alpha 36$ controls ALDH1 positive breast cancer cells. J Steroid Biochem Mol Biol. 2011; 127:262-268.

16. Li C, Wang Y, Wang S, Wu B, Hao J, Fan H, Ju Y, Ding Y, Chen L, Chu X, Liu W, Ye X, et al. HBV mRNAs-mediated miR-122 inhibition up-regulates PTTG1-binding protein which promotes HCC tumor growth and cell invasion. J Virol. 2013; 87:2193-2205.

17. Paris L, Cecchetti S, Spadaro F, Abalsamo L, Lugini L, Pisanu ME, Iorio E, Natali PG, Ramoni C, Podo F. Inhibition of phosphatidylcholine-specific phospholipase $\mathrm{C}$ downregulates HER2 overexpression on plasma membrane of breast cancer cells. Breast Cancer Res. 2010; 12:R27.

18. Hou J, Li X, Li C, Sun L, Zhao Y, Zhao J, Meng S. Plasma membrane gp96 enhances invasion and metastatic potential of liver cancer via regulation of UPAR. Mol Oncol. 2015; 9:1312-1323.

19. Nawaz Z, Lonard DM, Dennis AP, Smith CL, O'Malley BW. Proteasome-dependent degradation of the human estrogen receptor. Proc Natl Acad Sci U S A. 1999; 96:1858-1862.

20. Wijayaratne AL, McDonnell DP. The human estrogen receptor-alpha is a ubiquitinated protein whose stability is affected differentially by agonists, antagonists, and selective estrogen receptor modulators. J Biol Chem. 2001; 276:35684-35692.

21. Reid G, Denger S, Kos M, Gannon F. Human estrogen receptor-alpha: regulation by synthesis, modification and degradation. Cell Mol Life Sci. 2002; 59:821-831.

22. Wang Z, Zhang X, Shen P, Loggie BW, Chang Y, Deuel TF. A variant of estrogen receptor-\{alpha\}, hER\{alpha\}36: transduction of estrogen- and antiestrogendependent membrane-initiated mitogenic signaling. Proc Natl Acad Sci U S A. 2006; 103:9063-9068.

23. Zhang Y, Cao S, Meng S, Gao GF. A strategy to produce monoclonal antibodies against gp96 by prime-boost regimen using endogenous protein and E. coli heterologouslyexpressed fragment. J Cent South Univ Technol. 2011; 18:1857-1864.

24. Lee LM, Cao J, Deng H, Chen P, Gatalica Z, Wang ZY. ER-alpha36, a novel variant of ER-alpha, is expressed in ER-positive and -negative human breast carcinomas. Anticancer Res. 2008; 28:479-483.

25. Vranic S, Gatalica Z, Deng H, Frkovic-Grazio S, Lee LM, Gurjeva O, Wang ZY. ER- $\alpha 36$, a novel isoform of ER- $\alpha 66$, is commonly over-expressed in apocrine and adenoid cystic carcinomas of the breast. J Clin Pathol. 2011; 64:54-57.

26. Lin SL, Yan LY, Liang XW, Wang ZB, Wang ZY, Qiao J, Schatten H, Sun QY. A novel variant of ER-alpha, ER-alpha36 mediates testosterone-stimulated ERK and Akt activation in endometrial cancer Hec1A cells. Reprod Biol Endocrinol. 2009; 7:102.

27. Deng H, Huang X, Fan J, Wang L, Xia Q, Yang X, Wang Z, Liu L. A variant of estrogen receptor-alpha, ER-alpha36 is expressed in human gastric cancer and is highly correlated with lymph node metastasis. Oncol Rep. 2010; 24:171-176.

28. Jiang $\mathrm{H}$, Teng R, Wang Q, Zhang X, Wang H, Wang Z, Cao J, Teng L. Transcriptional analysis of estrogen receptor alpha variant mRNAs in colorectal cancers and their matched normal colorectal tissues. J Steroid Biochem Mol Biol. 2008; 112:20-24.

29. Huang J, Chamness GC, Schiff R, Chang E, Osborne CK, Mao S, Wu Y, Jiang L, Lai Q, Wang Z, Hilsenbeck S. Nonnuclear human estrogen receptor-alpha $36(\mathrm{hER} \alpha-36)$ is expressed in ER, PR, and Her2 positive or negative breast cancer patients as well as cell lines, and physically interacts with Her2. Cancer Res. 2008; 68:5174. 
30. Kang L, Zhang X, Xie Y, Tu Y, Wang D, Liu Z, Wang ZY. Involvement of estrogen receptor variant ER-alpha36, not GPR30, in nongenomic estrogen signaling. Mol Endocrinol. 2010; 24:709-721.

31. Chaudhri RA, Olivares-Navarrete R, Cuenca N, Hadadi A, Boyan BD, Schwartz Z. Membrane estrogen signaling enhances tumorigenesis and metastatic potential of breast cancer cells via estrogen receptor- $\alpha 36$ (ER $\alpha 36)$. J Biol Chem. 2012; 287:7169-7181.

32. Acconcia F, Ascenzi P, Bocedi A, Spisni E, Tomasi V, Trentalance A, Visca P, Marino M. Palmitoylationdependent estrogen receptor alpha membrane localization: regulation by 17 beta-estradiol. Mol Biol Cell. 2005; 16:231-237.
33. Shi YE, Chen Y, Dackour R, Potters L, Wang S, Ding Q, Wang Z, Liu YE. Synuclein gamma stimulates membraneinitiated estrogen signaling by chaperoning estrogen receptor (ER)-alpha36, a variant of ER-alpha. Am J Pathol. 2010; 177:964-973.

34. Zhao B, Wang Y, Wu B, Liu S, Wu E, Fan H, Gui M, Chen L, Li C, Ju Y, Zhang W, Meng S. Placenta-derived gp96 as a multivalent prophylactic cancer vaccine. Sci Rep. 2013; 3:1947.

35. Messmer MN, Pasmowitz J, Kropp LE, Watkins SC, Binder RJ. Identification of the cellular sentinels for native immunogenic heat shock proteins in vivo. J Immunol. 2013; 191:4456-4465. 